\title{
Changes to the Healthy Kids Check: will we get it right?
}

\section{Are we at risk of over-medicalising and under-researching?}

n 2011, the Australian Government announced plans to change the voluntary Healthy Kids Check (HKCheck) during 2012-2013, ${ }^{1}$ by lowering the age of screening to children aged 3 years and incorporating elements of social and emotional wellbeing. The HKCheck will be conducted by general practitioners, practice nurses and Aboriginal health workers, and will cost about $\$ 11$ million over 5 years. $^{2}$

The Expert Working Group developing the HKCheck has not made public what the check comprises and what screening will be involved. While the first media release focused on 3-year-olds and "social and emotional development", the most recent release (March 2013) announced that the expanded HKCheck will be phased in initially in eight Medicare Local areas in 2013, and the target group will be children aged from $3 \frac{11}{2}$ to 5 years. ${ }^{3}$

It is not clear from the latest media release if social and emotional development will be included, and whether the HKCheck will identify "at-risk" families (ie, those with risk factors for children with psychological, conduct and behavioural problems) or whether it will identify risk factors for childhood psychiatric disorders. One aim of a population screening program, such as the HKCheck, is to ensure support for children by identifying and referring families to an appropriate health professional for an indepth assessment and appropriate intervention (if initial primary health screening finds children who potentially would benefit from this).

Conducting population screening raises a number of complex issues. We will discuss the potential health benefits and risks of population social-emotional screening of children 3-4 years of age, and propose options based on currently available evidence. The first 3 years of life are crucial in terms of neurodevelopment - trauma, stress and/or attachment disruption may have adverse effects on brain and psychological development. ${ }^{4}$ Early adversity is associated with a range of later difficulties in multiple domains in life, including development and psychiatric disorders; ${ }^{4}$ however, this important topic is beyond the scope of our article.

\section{Screening for mental health in early childhood}

Social and emotional wellbeing in early childhood is defined as a "young child's capacity to experience, regulate
Michael F Daubney MB BS, FRANZCP, Child Psychiatrist

Cate M Cameron $\mathrm{PhD}, \mathrm{MPH}$, BSocWork(Hons), Senior Research Fellow

Paul A Scuffham $\mathrm{PhD}, \mathrm{BA}$, Chair in Health Economics, Griffith Health Institute

School of Medicine, Griffith University Logan Campus, Brisbane, QLD.

michael_daubney@ bigpond.com

doi: 10.5694/mjal2.11455

rel

is early detection, while minimising false positives. ${ }^{6}$ Risks of screening include over-medicalising (ie, interpreting normal and individual variation or transient disturbances as psychopathological conditions); not identifying relationship disturbances; and labelling (with the associated stigma). Finally, screening is potentially very costly.

Currently, there are a number of clinical instruments that examine social and emotional development in 3-yearolds.

- The one-page Pediatric Symptom Checklist, for use by paediatricians, is a brief assessment from parental reporting of dysfunction in major areas of a child's daily life. A positive score suggests the need for further evaluation by a qualified mental health worker. This instrument has a specificity of $68 \%$ and a sensitivity of $95 \%$ when compared with clinicians' ratings of children's psychosocial dysfunction. ${ }^{7}$ - The Child Behavior Checklist (CBCL/1.5-5) for ages $1 \frac{1}{2}-5$ years has good reliability and validity, but is lengthy (99 items). ${ }^{8}$ It is not a screening instrument, but is used as part of a comprehensive assessment by experienced clinicians.

- The 11-item Brief Infant-Toddler Social and Emotional Assessment (BITSEA) assesses social-emotional abilities, such as empathy, prosocial behaviours and compliance, up to age 36 months and takes about 10 minutes to complete. ${ }^{9}$ Research has shown that its internal Online first 22/04/13 $\quad$ consistency and inter-rater reliability are marginal. ${ }^{10}$ 
- The Ages and Stages Questionnaire - Social Emotional (ASQ-SE) is a comprehensive tool for screening possible delays in social-emotional and developmental functioning in children. It takes 15 minutes to complete and its sensitivity has been found to be $71 \%-85 \% .^{11}$

- Parents' Evaluation of Developmental Status (PEDS) is a brief screening tool for developmental and behavioural screening and ongoing surveillance of children from birth through to 8 years of age. Summary psychometric figures are sensitivity $86 \%$ and specificity $74 \%$. However, only two specific questions concern mental health issues, and its validity testing (that it measures what it purports to measure) is mainly derived from overall development and not specifically social-emotional development. ${ }^{12}$

While the BITSEA and ASQ-SE were developed as clinical screening tools, they were not designed for largescale population screening. These instruments may be used in a number of clinical settings, although they are most easily applied where time is not an issue and by those who have in-depth knowledge of child development (eg, staff of child health clinics). The CBCL/1.5-5, the BITSEA and the ASQ-SE need to be purchased and require training to score.

In summary, none of these tools meets all requirements for a brief population screen of children's social-emotional development.

\section{Is it possible to characterise psycho- pathological conditions in early childhood?}

The same clustering of symptoms seen in 3-year-olds also occurs in older children and adolescents, and these symptom clusters are associated with socioemotional impairment, including social problems or a negative impact on the family. Studies using available validated instruments and clinical assessment have found the most prevalent clusters to be anxiety disorders, attention deficit hyperactivity disorder (ADHD), depressive disorder and behavioural difficulties. ${ }^{13}$ Kowalenko notes a range of prevalence figures of $7 \%-26 \%$, reflecting the need for caution in interpreting these data and for further research. ${ }^{13}$ Another population study reported prevalence rates of impairment of 7\%-11\% (Diagnostic and statistical manual of mental disorders [DSM-IV]) in children entering school. $^{14}$

Some problem behaviours and symptoms in early childhood are not transient. Typically, research in this area involves measuring internalising (eg, anxiety $\left.{ }^{15}\right)$ and/or externalising (eg, aggression ${ }^{15}$ ) symptoms, or specific symptoms, including attention problems ${ }^{15}$ and posttraumatic stress disorder. ${ }^{16}$ In general, studies suggest moderate continuity of symptoms (although most studies are not continued into adolescence), and there can be a change in symptom presentation over time. ${ }^{17}$ Children who frequently engage in externalising or internalising problem behaviours are at greater risk of a range of negative long-term outcomes, including dropping out of school and incarceration. ${ }^{18,19}$ A repeated finding is that elevated aggression persists from the age of 3 years to middle childhood. Currently, there is no research showing screening results at 3 years being predictive of specific psychopathological conditions in adulthood. ${ }^{20}$

Risk factors identified for symptom clusters in 3-yearolds are similar to those in older children. ${ }^{21}$ For example, there is evidence of long-term implications of early impairment, including that caused by parental mental health problems. ${ }^{4}$ Relatively few empirical studies have quantified the long-term predictive strength of these risk factors, when measured at, or near, the age of school entry. The moderating and mediating variables (eg, family factors, socioeconomic status) associated with the persistence of difficulties are typically not included in current screening measures.

\section{Potential benefits of screening}

Waiting to screen, identify and intervene may leave children "at risk" and miss opportunities for early intervention, prevention and improved trajectories, resulting in loss of both health and future economic benefits. ${ }^{22}$ Psychosocial problems are increasingly difficult to change or correct at an older age, but a meta-analysis has demonstrated the effectiveness of intervention in early childhood. ${ }^{23}$ However, similar to older children, younger children generally do not receive interventions because the problems remain undetected..$^{24}$ From a broader perspective, identifying high-risk or symptomatic young children, and providing accurate prevalence estimates, would enable appropriate funding for the health and educational services necessary to support these children and their families.

\section{Limitations and barriers associated with screening}

As well as the previously noted risks, there are challenges in terms of both GPs using screening instruments and parents attending services offered. ${ }^{25}$ While there is research highlighting some of the short-term and longerterm problems in at-risk groups, developmental psychopathology is complex and it may not be possible to design a screening tool that can accurately identify young children who will develop disorders in the future.

Emotional and behavioural symptoms in young children are a final common pathway produced by multiple possible aetiologies requiring individual treatment planning. It is currently unclear which domains a screening instrument should include.

Evidence-based early intervention programs have often involved economically disadvantaged families. While there are well researched early intervention programs, some programs were shown not to be beneficial and, until further evidence is available, some scepticism remains about the universal application of early intervention programs. ${ }^{5}$ Is it better to have a population-based approach to treatment that does not need screening, or screening that leads to more targeted interventions? Further research is needed. 


\section{Perspectives}

Children identified as being in need of more assessment may overwhelm currently available Australian health care resources. Jureidini and Raven note that interventions must be widely and equitably available to those who screen positive and, when targeted to those with "predisease", should effectively reduce the likelihood of developing disorders. ${ }^{26}$

\section{Future options}

Given current knowledge, two fundamental steps are needed. First, we need to invest in methodologically robust, longitudinal population studies, starting before birth, which include risk factors and multiple outcome parameters. This information combined with that from the Australian Early Development Index (a population tool used in the first year of school, measuring five domains of children's development) ${ }^{27}$ would provide much needed data on norms for Australian 3-year-olds to assist service planning.

Second, rather than spending money on screening that lacks an evidence base, a logical first step would be to develop a population-based screening instrument. One possible strategy would be to modify existing instruments to make them briefer. Alternatively, we could design a new instrument following best practice, after a comprehensive review of the existing literature, and obtain expert advice to ascertain which domains to include (infant, infant-parent interaction, family interaction). Then factor analysis and psychometric testing could be used to validate a brief population-screening version. Finally, its applicability in broader contexts could be assessed, including in different cultures.

Despite good intentions, further research and planning are needed before starting large-scale, population socialemotional screening of 3-year-old children in Australia.

Acknowledgements: We wish to acknowledge Dr James Scott for his assistance in the preparation of this article.

Competing interests: No relevant disclosures.

Provenance: Not commissioned; externally peer reviewed.

1 National Mental Health Reform 2011-12. http://www.health.gov.au/internet/ publications/publishing.nsf/Content/nmhrl1-12 nmhrll-12-priorities children (accessed Apr 2013).

2 Butler M. Child health experts to develop new healthy kids check [media release]. 30 September 2011. http://www.health.gov.au/internet/ministers/ publishing.nsf/Content/mr-yrll-mb-mbll6.htm?OpenDocument\&yr= 2011\&mth=09 (accessed Mar 2013).

3 Butler M. Improved kids' health check to begin [media release]. 3 March 2013. http://www.health.gov.au/internet/ministers/publishing.nsf/Content/ mr-yrl3-mb-mb005.htm (accessed Apr 2013).

4 Newman L. Getting in early: identification of risk in early childhood. Aust N Z J Psychiatry 2012; 46: 697-699.
5 Zeanah CH Jr, Zeanah PD. The scope of infant mental health. In: Zeanah CH Jr, editor. Handbook of infant mental health. 3rd ed. New York: Guilford Press, 2009: 5-21.

6 Barker DJP, Cooper C, Rose CP. Epidemiology in medical practice. 5th ed. Edinburgh: Churchill Livingstone, 1998: 122-130.

7 Jellinek MS, Murphy JM. The recognition of psychosocial disorders in pediatric office practice: the current status of the pediatric symptom checklist. J Dev Behav Pediatr 1990; 11: 273-278.

8 Achenbach TM, Rescorla LA. Manual for the ASEBA preschool forms and profiles: an integrated system of multi-informant assessment. Burlington, Vt: University of Vermont, Research Center for Children, Youth, \& Families, 2000.

9 Briggs-Gowan MJ, Carter AS, Irwin JR, et al. The Brief Infant-Toddler Social and Emotional Assessment: screening for social-emotional problems and delays in competence. J Pediatr Psychol 2004; 29: 143-155.

10 Caselman TD, Self PA. Assessment instruments for measuring young children's social-emotional behavioral development. Children Schools 2008; 30: 103-115. doi: 10.1093/cs/30.2.103.

11 Minnesota Department of Health. Developmental and social-emotional screening of young children ( $0-6$ years of age) in Minnesota. Ages and Stages Questionnaire - Social Emotional (ASQ-SE). http://www.health.state.mn.us/ divs/fh/mch/devscrn/instr/asqse.html (accessed Mar 2013).

12 Glascoe FP. Parents' Evaluation of Developmental Status (PEDS). Nolensville, Tenn: PEDSTest.com, LLC, 2010. http://www.pedstest.com (accessed Mar 2013).

13 Kowalenko NM. The three year old social and emotional well-being check is good news. Aust N Z J Psychiatry 2012; 46: 928-931.

14 Carter AS, Wagmiller RJ, Gray SA, et al. Prevalence of DSM-IV disorder in a representative, healthy birth cohort at school entry: sociodemographic risks and social adaptation. J Am Acad Child Adolesc Psychiatry 2010; 49: 686-698.

15 Brassard MR, Boehm AE. Assessment of emotional development and behavior problems. In: Preschool assessment: principles and practices. New York: Guilford Press, 2007: 508-576.

16 Scheeringa MS, Zeanah CH, Myers L, Putnam FW. Predictive validity in a prospective follow-up of PTSD in preschool children. J Am Acad Child Adolesc Psychiatry 2005; 44: 899-906.

17 Beyer T, Postert C, Müller JM, Furniss T. Prognosis and continuity of child mental health problems from preschool to primary school: results of a fouryear longitudinal study. Child Psychiatry Hum Dev 2012; 43: 533-543.

18 Morgan PL, Farkas G, Wu Q. Kindergarten predictors of recurring externalizing and internalizing psychopathology in the third and fifth grades. J Emot Behav Disord 2009; 17: 67-79. doi: 10.1177/1063426608324724.

19 Campbell SB, Spieker S, Burchinal M, Poe MD; NICHD Early Child Care Research Network. Trajectories of aggression from toddlerhood to age 9 predict academic and social functioning through age 12.J Child Psychol Psychiatry 2006; 47: 791-800.

20 Najman JM, Heron MA, Hayatbakhsh MR, et al. Screening in early childhood for risk of later mental health problems: a longitudinal study. J Psychiatr Res 2008; 42: 694-700.

21 Bayer JK, Ukoumunne OC, Mathers M, et al. Development of children's internalising and externalising problems from infancy to five years of age. Aust N Z J Psychiatry 2012; 46: 659-668.

22 Knudsen El, Heckman JJ, Cameron JL, Shonkoff JP. Economic, neurobiological, and behavioral perspectives on building America's future workforce. Proc Natl Acad SciU S A 2006; 103: 10155-10162.

23 Bakermans-Kranenburg MJ, van IJzendoorn MH, Juffer F. Less is more: metaanalyses of sensitivity and attachment interventions in early childhood. Psychol Bull 2003; 129: 195-215.

24 Jensen PS, Goldman E, Offord D, et al. Overlooked and underserved: "action signs" for identifying children with unmet mental health needs. Pediatrics 2011; 128: 970-979.

25 Weitzman CC, Leventhal JM. Screening for behavioral health problems in primary care. Curr Opin Pediatr 2006; 18: 641-648.

26 Jureidini J, Raven M. Healthy Kids Check: lack of transparency and misplaced faith in the benefits of screening. Aust NZ J Psychiatry 2012; 46: 924-927.

27 Centre for Community Child Health. Australian Early Development Index: building better communities for children. Final evaluation report, 2007. http://www.rch.org.au/emplibrary/australianedi/AEDI_Final_Evaluation Report_March_07.pdf (accessed Mar 2013). 